\title{
Prevalence and Risk Factor Analysis of Acute Respiratory tract Infections in Rural areas of Kashmir valley under 5 Years of Age
}

\author{
Abid Ali Mir, Imtiyaz A, Anjum Fazili, Javeed Iqbal', Rohul Jabeen and Anjali Salathia \\ Department of Community Medicine and Department of Pediatrics*, SKIMS Soura, Srinagar Kashmir, India.
}

\section{ABSTRACT}

Research Question: How important is acute respiratory tract infections in children less than 5 years of age and what are the main factors that need attention. Objective: To determine the magnitude of ARI under 5 years of age in rural areas of Kashmir valley. 2) To identify various risk factors responsible for ARI. Methodology: Community based Cross sectional study using multistage sampling procedure was used to study 1644 children. A house to house survey was carried out in the defined geographical region in order to determine the prevalence and risk factors of ARI less than 5 years of age. Results: Among 1644 children under 5 years of age studied, 886 (53.89\%) were males and 758 (46.11\%) female. An overall prevalence of $21.41 \%$ under 5 years of age was observed in a Kashmir valley. The prevalence of ARI varied according to the age of child being $19.3 \%$ in age group of $0-1$ years, $23.0 \%$ in $1-3$ years and $20.4 \%$ in age group of 3-5 years. Prevalence of ARI was more $(22.5 \%)$ in male children as compared to female $(20.05 \%)$ children $[P>0.05]$. The socio demographic variables that showed a significant relationship with ARI prevalence were parental literacy status $(\mathrm{OR}=1.806 ; \mathrm{Cl}=1.333-2.447 ; \mathrm{P}<0.05)$ and more so the Mother's literacy status $(\mathrm{OR}=1.635$; $\mathrm{Cl}=1.284-2.083 ; \mathrm{P}<0.05)$. ARI risk being high among Malnourished children $(\mathrm{OR}=2.38 ; \mathrm{Cl}=1.804-3.157 ; \mathrm{P}<0.05)$, inappropriately immunized children $(\mathrm{OR}=2.41 ; \mathrm{Cl}=1.853-3.154, \mathrm{P}<0.05)$, children lacking exclusive Breast feeding $(\mathrm{OR}=4.854 ; \mathrm{Cl}=3.735-6.309 ; \mathrm{P}<0.05)$ or put on early or delayed weaning $(\mathrm{OR}=1.66 ; \mathrm{Cl}=1.302-2.140 ; \mathrm{P}<0.05)$. Environmental / housing variables also showed significant association with $\mathrm{ARI}$ with risk being high in children living in poor ventilation $(\mathrm{OR}=4.865 ; \mathrm{Cl}=3.78-6.259 ; \mathrm{P}<0.05)$, overcrowded houses $(\mathrm{OR}=1.829 ; \mathrm{Cl}=1.442-2.320$; $\mathrm{P}<0.05)$, houses with kitchen not separate (OR $=1.829, \mathrm{Cl}=1.442-5.481, \mathrm{P}<0.05)$, and using cooking fuel other than $L P G(O R=2.063 ; \mathrm{Cl}=1.615-2.634 ; \mathrm{P}<0.05)$ Conclusion: Besides sensitizing mothers on childhood nutritional (exclusive breast feeding and early / delayed weaning) and immunization the role of environmental /housing variables (Poor ventilation, over crowding, combined kitchen and use of cooking fuel other than LPG) need attention.

Keywords: Prevalence, ARI, risk factors

Abbreviations: ARI: Acute Respiratory Infections; LPG: Liquefied Petroleum Gas; OR: Odds Ratio; CI: Confidence Interval; NFHS: National Family Health Survey; WHO: World Health Organization; SPSS: Statistical Package for Social Sciences.

\section{INTRODUCTION}

Globally Acute Respiratory Infections (ARI) in young children is responsible for an estimated 3.9 million deaths worldwide annually. About $90 \%$ of ARI deaths

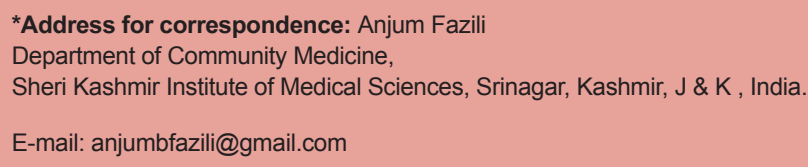

DOI: 10.5530/ijmedph.2.3.10 are due to the pneumonia, which is usually bacterial in origin. ${ }^{1}$ On an average, child below 5 yrs age suffer about 4-5 episodes of ARI per year, thus accounting for about 238 million attacks. Consequently, although most of the attacks are mild \& self-limiting episodes, yet ARI is responsible for about $30-50 \%$ of visits to the health facilities and about $20-40 \%$ of admissions to the hospitals. $^{2}$ It is also a leading cause of disabilities including deafness as sequel of otitis media. ${ }^{3}$ In India, ARI is one of the major causes of hospitalization and mortality in fewer than fives. Hospital records from states with high 
infant mortality rates show that up to $13 \%$ of inpatient deaths in pediatrics wards are due to ARI. The proportion of deaths due to ARI in the community is much higher as many children die at home. ${ }^{4}$ The reason for high case fatality may be that children are either not brought to the hospitals or brought too late.

State of Jammu \& Kashmir topographically and climatically distinct state passes through all the four seasons of a year which are likely to have more impact on respiratory burden of diseases in children because it predisposes to various risk factors like overcrowding, indoor air pollution, low socio economic conditions. The present study is an attempt to study the prevalence and risk factors analysis of ARI in Kashmir valley.

\section{MATERIALS AND METHODS}

Present study was a cross-sectional study design, taken up in the rural areas of Kashmir valley. Children below 5 years ( $0-5$ year's age group) were selected randomly from three districts of Kashmir valley. Based on prevalence of ARI under 5 yrs of age as per NFHS-II data, sample size was calculated at $5 \%$ risk with $10 \%$ allowable error, which is equal to about 1500. A multistage population proportion to size procedure was adopted. In final stage of sampling the unit of study was households selected from various villages obtained through random selection. The selected child population of less than 5 years obtained was enrolled and inquiry suggestive of respiratory infection as per standard WHO case definition, classification and severity of ARI was recorded.

A pretested semi open ended questioner was used in the study to gather the information. The standard criteria for socio - economic status. ${ }^{5}$ Housing standard ${ }^{6}$ of the family, nutritional status ${ }^{7}$ of children has been used. The data thus collected has been fed to computer based spread sheet (SPSS 11.5 version no.) for data analysis. Desired tabulation, statistical analysis and standard tests of significance including chi-square test, bivariate analysis and multilogistic regression analysis have been applied.

\section{RESULTS}

1644 children under 5 years age group comprising of 886 $(53.89 \%)$ males and $758(46.11 \%)$ females were studied. $19.5 \%$ children were in the age group of $0-1$ year, $45.43 \%$ in the age group of $1-3$ years and $35.04 \%$ in the age group of $3-5$ years with a Mean age of $2.34+1.21 \mathrm{yrs}$. About $30 \%$ children had their both parents illiterate whereas
$1 / 3^{\text {rd }}(34.13 \%)$ children had both their parent's literate and $35.95 \%$ children had only single parent mostly father literate. Almost one-fifth $(19.46 \%)$ children were of birth $1^{\text {st }}$, $1 / 3$ rd $(32.97 \%)$ of $2^{\text {nd }}$ birth order, $31.33 \%$ of birth order $3^{\text {rd }}$ while rest belonged to higher birth orders. The median birth order of the studied children was 2.00. A small percentage $(7.42 \%)$ of children belonged to SES class-I whereas majority belonged to class-111 or class-1V (Table 1).

Nutritional and immunization status of the studied children in our study showed that majority of children were properly nourished $(83 \%)$ and only $17 \%$ were under nourished. Also, large percentage of children $(79.87 \%)$ had received proper immunization however less than $1 / 5^{\text {th }}$ of the studied population had not received appropriate immunization.

\begin{tabular}{|c|c|c|c|}
\hline \multirow[t]{2}{*}{ S.No } & \multirow{2}{*}{$\begin{array}{l}\text { Socio - Demographic } \\
\text { Characteristics }\end{array}$} & \multicolumn{2}{|c|}{ Total } \\
\hline & & NO. & $(\%)$ \\
\hline \multirow[t]{5}{*}{01.} & Age in Years & & \\
\hline & $0-1$ year & 321 & (19.06) \\
\hline & $1-3$ years & 747 & (44.35) \\
\hline & $3-5$ years & 576 & (34.20) \\
\hline & All Age Groups & 1644 & $(100)$ \\
\hline \multirow[t]{3}{*}{02.} & Gender & & \\
\hline & Male & 886 & $(53.8)$ \\
\hline & Female & 758 & $(46.10)$ \\
\hline \multirow[t]{4}{*}{03.} & Fathers Literacy Status & & \\
\hline & Illiterate & 693 & $(42.15)$ \\
\hline & Secondary & 507 & $(30.8)$ \\
\hline & Intermediate \& above & 444 & $(27.00)$ \\
\hline \multirow[t]{4}{*}{04.} & Mothers Literacy Status & & \\
\hline & Illiterate & 882 & $(53.64)$ \\
\hline & Secondary & 447 & (27.18) \\
\hline & Intermediate \& above & 315 & (19.16) \\
\hline \multirow[t]{6}{*}{05.} & Birth Order & & \\
\hline & 1 & 320 & (19.46) \\
\hline & 2 & 542 & (32.97) \\
\hline & 3 & 515 & (31.33) \\
\hline & 4 & 253 & (15.39) \\
\hline & 5 & 14 & $(0.85)$ \\
\hline \multirow[t]{4}{*}{06.} & Fathers Occupation & & \\
\hline & Unskilled & 643 & (39.11) \\
\hline & Semi skilled & 849 & (51.64) \\
\hline & Skilled & 152 & $(9.25)$ \\
\hline \multirow[t]{3}{*}{07} & Mothers Occupation & & \\
\hline & Nonworking & 1291 & (78.53) \\
\hline & Working & 25 & $(1.52)$ \\
\hline \multirow[t]{7}{*}{08.} & Socio Economic Status & & \\
\hline & Upper & 122 & $(7.42)$ \\
\hline & Upper middle & 378 & (22.99) \\
\hline & Average middle & 589 & (35.83) \\
\hline & Lower middle & 510 & (31.02) \\
\hline & Poor & 45 & $(2.7)$ \\
\hline & Total & 1644 & $(100)$ \\
\hline
\end{tabular}


Table 2: Prevalence of ARI in Kashmir Valley

\begin{tabular}{|c|c|c|c|c|c|c|c|}
\hline \multirow[t]{2}{*}{ Age } & \multirow{2}{*}{ Variables } & \multirow{2}{*}{ Total } & \multicolumn{2}{|c|}{ RESPIRATORY TRACT INF. } & \multirow{2}{*}{ Prev. } & \multirow{2}{*}{$X^{2}$} & \multirow{2}{*}{ P. Value } \\
\hline & & & Present (\%) & Absent (\%) & & & \\
\hline & $0-1$ year & 321 & 62 & 259 & $19.3 \%$ & & \\
\hline & $1-3$ years & 747 & 172 & 575 & $23.0 \%$ & 2288 & $>05(319)$ \\
\hline & $3-5$ years & 576 & 118 & 458 & $20.4 \%$ & 2.280 & $>.00(.519)$ \\
\hline & Total & 1644 & 352 & 1292 & $21.41 \%$ & & \\
\hline \multirow[t]{3}{*}{ Sex } & Males & 886 & 200 & 686 & $22.5 \%$ & & \\
\hline & Females & 758 & 152 & 606 & $20.05 \%$ & 1.542 & $>.05(.214)$ \\
\hline & Total & 1644 & 352 & 1292 & $21.41 \%$ & & \\
\hline
\end{tabular}

Overall prevalence of ARI was found to be $21.41 \%$ under the age of 5 years in Kashmir valley. The prevalence of ARI being $19.3 \%$ in age group of $0-1$ year, $23.0 \%$ in $1-3$ years of age and $20.4 \%$ in the age group of $3-5$ years. The prevalence of ARI was higher among male children $(22.5 \%)$ compared to female children (20.05\%) (Table 2). Prevalence of ARI was higher in children whose parents were illiterate, living in poorly ventilated and overcrowded homes with combined kitchen and using cooking fuel other than LPG. Similarly, malnourished and incompletely immunized children get ARI more likely than well nourished and completely immunized children.

Bivariate analysis showed significant association between Mother's literacy status and ARI risk $(\mathrm{OR}=1.635$; $\mathrm{CI}=1.284-2.083 ; \mathrm{p}<.05)$, however other variables $\mathrm{did}$ not show significantly any risk (Table 3 ).
Malnutrition among children had ARI risk 2.5 times $(\mathrm{OR}=2.38 ; \mathrm{CI}=1.804-3.157)$ than normal nourished children, Inappropriate immunization increased the risk by 2.4 times $(\mathrm{OR}=2.41 ; \mathrm{CI}=1.853-3.154)$, lack of exclusive breastfeeding by 5 times $(\mathrm{OR}=4.854$; $\mathrm{CI}=3.735-6.309)$, Early or delayed weaning by 1.7 times $(\mathrm{OR}=1.66$; $\mathrm{CI}=1.302-2.140$ ) among studied children. (Table 4)

The risk of ARI was 5 folds greater $(\mathrm{OR}=4.865$; $\mathrm{CI}=3.781-6.259)$ among children living in poorly ventilated houses, 4.3 times more $(\mathrm{OR}=4.295$; $\mathrm{CI}=3.355-5.497)$ among children living in overcrowded houses, and twice among children living in Common kitchen and living room $(\mathrm{OR}=1.829$; $\mathrm{CI}=1.442-2.320)$ (Table 5). Even poor domestic environment like Use of cooking fuel other than LPG was associated with 2 times greater risk $(\mathrm{OR}=2.063 ; \mathrm{CI}=1.615-2.634)$.

\begin{tabular}{|c|c|c|c|c|c|c|c|c|}
\hline & & & \multicolumn{2}{|c|}{ RESP. TRACT INFECTION } & \multirow[b]{2}{*}{ Prevalence(\%) } & \multirow[b]{2}{*}{ Odds ratio } & \multirow[b]{2}{*}{ C.I } & \multirow[b]{2}{*}{ P. value } \\
\hline & & & Present & Absent & & & & \\
\hline \multirow[t]{3}{*}{$\overline{01 .}$} & Age (Months) & & & & & & & \\
\hline & $\leq 12$ months & 316 & 57 & 259 & 18.04 & 0.771 & $0.563-1.056$ & $>0.05$ \\
\hline & $\geq 12$ months & 1328 & 295 & 1033 & 22.22 & & & \\
\hline \multirow[t]{3}{*}{02.} & Sex & & & & & & & \\
\hline & Male & 886 & 200 & 686 & 22.57 & 1.16 & $0.917-1.474$ & $>0.05$ \\
\hline & Female & 758 & 152 & 606 & 20.05 & & & \\
\hline \multirow[t]{3}{*}{03.} & Fathers Literacy & & & & & & & \\
\hline & Illiterate & 693 & 166 & 527 & 23.95 & 1.29 & $1.023-1.641$ & $>0.05$ \\
\hline & Literate & 951 & 186 & 765 & 19.56 & & & \\
\hline \multirow[t]{3}{*}{04.} & Mothers Litracy & & & & & & & \\
\hline & Illiterate & 882 & 222 & 660 & 25.17 & 1.63 & $1.284-2.083$ & $<0.05$ \\
\hline & Literate & 762 & 130 & 632 & 17.06 & & & \\
\hline \multirow[t]{3}{*}{05.} & Birth Order & & & & & & & \\
\hline & $\leq 2$ & 862 & 179 & 683 & 20.76 & 0.92 & $0.728-1.166$ & $>0.05$ \\
\hline & $\geq 2$ & 782 & 173 & 608 & 22.12 & & & \\
\hline \multirow[t]{3}{*}{07.} & Father's Occupation & & & & & & & \\
\hline & Unskilled & 643 & 142 & 501 & 22.08 & 1.06 & $0.840-1.36$ & $>0.05$ \\
\hline & Skilled & 1001 & 210 & 791 & 20.98 & & & \\
\hline \multirow[t]{3}{*}{08.} & Mother's Occupation & & & & & & & \\
\hline & Workers & 25 & 5 & 20 & 20.00 & 0.92 & $0.42-2.826$ & $>0.05$ \\
\hline & Non-workers & 1619 & 347 & 1272 & 21.43 & & & \\
\hline \multirow[t]{3}{*}{09.} & Socio Economic Status & & & & & & & \\
\hline & $\begin{array}{l}\text { Average middle \& } \\
\text { above }\end{array}$ & 1089 & 158 & 931 & 14.50 & 0.31 & $0.12-1.96$ & $>0.05$ \\
\hline & Lower middle \& below & 555 & 194 & 361 & 34.95 & & & \\
\hline
\end{tabular}


Table 4: Bivariate Relationship Between Nutrition, Immunization status, Breast feeding and Weaning with ARI

\begin{tabular}{|c|c|c|c|c|c|c|c|c|}
\hline & & & \multicolumn{2}{|c|}{ Resp. Tract Infection } & \multirow[b]{2}{*}{ Prevalence (\%) } & \multirow{2}{*}{$\begin{array}{l}\text { Odds } \\
\text { ratio }\end{array}$} & \multirow[b]{2}{*}{ C.I } & \multirow[b]{2}{*}{ p. value } \\
\hline & & & Present & Absent & & & & \\
\hline \multirow[t]{3}{*}{01.} & Mid Arm Circumf. & & & & & \multirow{3}{*}{2.38} & \multirow{3}{*}{$1.804-3.157$} & \multirow{3}{*}{$<0.05$} \\
\hline & $\begin{array}{l}\text { Malnourished } \\
\text { (Mod to severe) }\end{array}$ & 281 & 99 & 182 & 35.23 & & & \\
\hline & Normal & 1363 & 253 & 1110 & 18.56 & & & \\
\hline \multirow[t]{3}{*}{02.} & Immunization Status & & & & & & & \\
\hline & Partial \& un-immunized & 331 & 115 & 216 & 34.74 & \multirow{2}{*}{2.41} & \multirow{2}{*}{$1.853-3.154$} & \multirow{2}{*}{$<0.05$} \\
\hline & Fully immunized & 1313 & 237 & 1076 & 18.05 & & & \\
\hline \multirow[t]{3}{*}{03.} & Breast Feeding & & & & & \multirow{3}{*}{4.85} & \multirow{3}{*}{$3.735-6.309$} & \multirow{3}{*}{$<0.05$} \\
\hline & Predominant \& partial & 730 & 259 & 471 & 35.48 & & & \\
\hline & Exclusive & 914 & 93 & 821 & 10.17 & & & \\
\hline \multirow[t]{3}{*}{04.} & Weaning & & & & & & & \\
\hline & Early \& delayed & 956 & 238 & 718 & 24.89 & \multirow{2}{*}{1.66} & \multirow{2}{*}{$1.302-2.140$} & \multirow{2}{*}{$<0.05$} \\
\hline & Proper & 688 & 114 & 574 & 16.56 & & & \\
\hline
\end{tabular}

Table 5: Bivariate Relationship Between Environmental Variables and ARI

\begin{tabular}{|c|c|c|c|c|c|c|c|c|}
\hline & & & \multicolumn{2}{|c|}{ Resp. Tract Infection } & \multirow{2}{*}{ Prevalence (\%) } & \multirow{2}{*}{ Odds ratio } & \multirow{2}{*}{ C.I } & \multirow{2}{*}{ p. value } \\
\hline & & & Present & Absent & & & & \\
\hline 01. & Housing & & & & & \multirow{3}{*}{4.86} & \multirow{3}{*}{$3.781-6.259$} & \multirow[b]{3}{*}{$<0.05$} \\
\hline a) & Poor ventilation & 617 & 236 & 381 & 38.25 & & & \\
\hline b) & Adequate ventilation & 1027 & 116 & 911 & 11.29 & & & \\
\hline c) & Over crowding & 503 & 200 & 303 & 39.76 & \multirow{2}{*}{4.29} & \multirow{2}{*}{$3.355-5.497$} & \multirow{2}{*}{$<0.05$} \\
\hline d) & No over crowding & 1141 & 152 & 989 & 13.32 & & & \\
\hline 02. & Kitchen & & & & & & & \multirow{3}{*}{$<0.05$} \\
\hline a) & Not separate & 624 & 174 & 450 & 27.88 & \multirow{2}{*}{1.83} & \multirow{2}{*}{$1.442-2.320$} & \\
\hline b) & Separate & 1020 & 178 & 842 & 17.45 & & & \\
\hline 03. & Chula & & & & & & & \\
\hline a) & Hearth / Firewood & 492 & 150 & 342 & 30.48 & \multirow{2}{*}{2.06} & \multirow{2}{*}{$1.615-2.634$} & \multirow{2}{*}{$<0.05$} \\
\hline b) & LPG & 1152 & 202 & 950 & 17.53 & & & \\
\hline 04. & Smoking & & & & & & & \multirow{3}{*}{$>0.05$} \\
\hline a) & Present & 1343 & 285 & 1058 & 21.22 & \multirow{2}{*}{0.889} & \multirow{2}{*}{$0.661-1.196$} & \\
\hline b) & Absent & 301 & 70 & 231 & 23.26 & & & \\
\hline
\end{tabular}

Using stepwise multilogistic regression analysis, we observed the highest score for lack of exclusive breastfeeding (242.98) followed by poor ventilation (166.42), overcrowding (145), delayed weaning (49.38), inappropriate immunization (4.53), malnutrition (38.47), Chula used other than LPG (34.37) and parental literacy status (16.24) in a sequential order. That shows that these variables have maximum impact on the prevalence of ARI in children (Table 6).

\section{DISCUSSION}

Present study observed an overall prevalence of $21.41 \%$ under 5 years of age in rural areas of Kashmir valley. The prevalence of ARI varied according to the age of the child. Ranging from $19.3 \%$ to $23.0 \%$, being highest $(23.0 \%$ ) in 1-3 years of age group and lowest among infants $(19.3 \%)$, showing that the age group of $1-3$ years is more

\begin{tabular}{clccc}
\multicolumn{6}{l}{ Table 6: Multi - Logistic Regression Analysis } \\
\hline \multicolumn{1}{l}{ RANK } & \multicolumn{1}{c}{ Variables } & Score & Df & P-value \\
\hline 1. & Lack of breast feeding & 242.985 & 2 & .000 \\
2. & Poor ventilation & 166.424 & 1 & .000 \\
3. & Over crowding & 145.033 & 1 & .000 \\
4. & Delayed weaning & 49.382 & 2 & .000 \\
5. & Inappropriate immunization & 44.537 & 2 & .000 \\
6. & Malnutrition (Moderate/severe) & 38.471 & 1 & .000 \\
7. & Chula used (other than LPG) & 34.376 & 1 & .000 \\
8. & Kitchen (Not separate) & 25.047 & 1 & .000 \\
9. & Parental literacy (Illiterate) & 16.245 & 2 & .000 \\
10. & Gender & 1.542 & 1 & .214 \\
\hline
\end{tabular}

prone to acquire respiratory tract infections than infancy or post-toddler period. The probable reason for this variation may be receding of maternal immunity after the age of six months compounded by frequent handling by various persons in the family that may predispose them to ARI. Also, second year of life is vulnerable to Nutritional deficiencies due to inadequate and or inappropriate food intake as a result of poor knowledge on weaning practices 
that even lead to specific nutritional deficiency resulting in immuno-compromised status of a child to make him more susceptible to respiratory infections. The observed greater prevalence of ARI in male children (22.5\%) than among female children $(20.05 \%)$ could be because of the fact that the male sex is not only biologically vulnerable to acquire infections than its counterpart but also remains privileged to health seeking behavior than the female child. In a study on "Magnitude of ARI under 5 years", conducted by P. Chabra et $\mathrm{al}^{8}$ prevalence of ARI was recorded as $12.1 \%$ with a substantial decline in prevalence with age. Longitudinal study on ARI among rural under fives, conducted by Nilanjan kumar et $\mathrm{al}^{9}$ has also showed similar ARI prevalence of $19.57 \%$ among under 5 children with prevalence being highest in the age group of $2-3$ years.

Parental literacy showed inverse relationship with the ARI prevalence with much greater odds of acquiring respiratory disease in children if both parents' are illiterate or mother only is illiterate. The probable reason for this greater risk is related to better caring and rearing of children by literate mothers besides being more aware on health seeking behavior in childhood morbidity. The result runs in conformity with the study conducted by S. Broor et al. ${ }^{10}$ However, D'Souza RM et al ${ }^{11}$ did not observe maternal education a risk factor for ARI in his study.

Lack of exclusive breastfeeding, adhering to early or delayed weaning up-to 2 years and overall moderate to severe malnutrition among children were also observed as independent risk factors for ARI in children. Shah N et $\mathrm{al}^{12}$ showed that improper weaning and lack of exclusive breastfeeding was associated with increased risk of severe ARI in children. Azizi et $\mathrm{al}^{13}$ confirmed that breastfeeding for at least 4 months was an independent protective factor against ARI. Thus the findings reinforce the need to strengthen the promotion of exclusive breastfeeding in the first year with appropriate and correct weaning practices with nutritionally balanced foods. As expected children who were completely immunized for age were less likely to suffer from ARI compared to those incompletely immunized. The findings remain consistent with studies by Deb SK et a ${ }^{14}$ others. Significantly greater risk of ARI episodes were noted by Nilanjan Kumar et $\mathrm{al}^{9}$ among children who were not fully immunized $($ Risk Ratio $=2.76)$ thereby stressing the need to complete timely immunization in children.

The five folds $(\mathrm{OR}=4.86)$ greater risk observed among children living in poorly ventilated and overcrowded environment in the present study, shows that children in such environment contract respiratory infections much more than in well ventilated and non overcrowded settings. Cardosa MR et $\mathrm{al}^{15}$ in his study also showed that overcrowding appeared to be associated with two fold increase in the incidence of ARI. Barton et $\mathrm{al}^{16}$ found the significant association between ARI in children living in poorly ventilated and overcrowded houses. Higher ARI risk in children living in houses with combined kitchen and using cooking fuel other than LPG shows relationship of domestic microenvironment with ARI, an important factor usually not stressed or addressed during routine counseling of children. Kitchen in our society, especially in rural set-up is an important source of indoor pollution particularly the smoke from the chullas. Use of biomass fuel (wood, crop residues and animal dung) was a predominant contributor to the indoor air pollution. The biomass fuel burns with incomplete combustion generating a lot of toxic products that adversely affect the specific and non-specific local defenses of respiratory tract. ${ }^{17}$ The risks of respiratory infections is highest for children due to longer stay indoors and close proximity during cooking. Mishra $\mathrm{V}$ et $\mathrm{al}^{18}$ observed that children under three years of age living in households using wood or animal dung as their primary cooking fuel have one third higher risk of ARI than do the children living in households which uses cleaner fuel. $\mathrm{S}$. Broor et $\mathrm{al}^{10}$ in his study confirms similar observations. Hence, provision of clean fuels such as LPG and electricity, householder's education and modification of stove are potential measures to decrease this risk. For such intervention, local needs and community participation should receive high priority.

While assessing the impact level of various variables using rank order, lack of exclusive breast-feeding ranked the first in the risk rank obtaining the score of 242.985, thereby depicting that the lack of exclusive breastfeeding had the maximum impact on increased risk to ARI in children. This was followed by poor ventilation (166.424), overcrowding (145.033), delayed weaning (49.382), inappropriate immunization (44.537), malnutrition (38.471), type of Chula used (34.376), kitchen location (25.047) and parental illiteracy (16.245) in that order of importance. Our results do not confirm with ranking of risk factors by $\mathrm{S}$ Broor et $\mathrm{al}^{10}$ who reported that $1^{\text {st }}$ sibling of the child ranked is 24 times at risk than subsequent birth order children, children with incomplete immunizations have 2.85 times greater risk, use of cooking fuel other than LPG (2.5 times), malnutrition (1.85 times) and lack of exclusive breast feeding 
(1.6 times) are also at higher risk. One can infer that not only it is the combination of factors (rather a single factor) that attributes to increased risk of ARI but also different factors significantly have varying effect on increased risk for ARI in children under 5 years of age thereby supporting the hypothesis that under different setting (socio-cultural and geographic conditions), it is mandatory to assess and rank the risk factors for prioritizing the strategy to address the maximum impact reduction through available knowledge.

\section{CONCLUSIONS}

The present study has shown that most of the factors that are associated with ARI or had increased the risk of ARI are modifiable in nature. Even a minor modification can reduce the impact and decrease the present risk of ARI by a great deal. The need of the hour is to make the parents well aware about these modifiable risk factors and suggest methods or actions that can be undertaken to prevent exposure to such factors. Besides emphasizing and supporting exclusive breastfeeding practices, proper and timely weaning coupled with encouraging complete immunization of children, we also need to stress on domestic and micro environment for reducing prevalence of ARI. Parents need to be informed and educated regarding the consequences of overcrowding, poor ventilation, smoking in the family and use of smoking Chula. The above comprehensive approach needs to be thoroughly planned, efficiently managed and coordinated in the current ARI control program activities.

\section{BIBLIOGRAPHY}

1. Park's, text book of Preventive \& Social Medicine.18 Edition. Acute Respiratory Infections. 139-40.

2. Black R, S Morris and J Bryce. Where and why are 10 Million Children Dying Every Year. Lancet 2003. 361; 2226-34.

3. William B, eGouws and C Dye. Estimates of Worldwide Distribution of Child Deaths from ARI. Lancet Infectious Disease. 2002: 2; 25-32.

4. Bryce J, C. Boschi and E. Black. WHO Estimates of the Cause of Death in Children. Lancet 365; 1147-52.

5. Socio-economic status of the family was assessed by Prasad's method and is based on per capita family income (updated as per index for March 2003).

6. Govt of India (1949). Report of the Environmental Hygiene Committee, Ministry of Health, New Delhi.

7. Nutritional status of the children was assessed by the age independent criteria i.e, Mid-arm circumferences and classified as per IAP classification.

8. Chabra P and Garg S. Magnitude of ARI in under fives, New Delhi. Indian Pediatrics 1993, Nov.30: 1315-19.

9. Nilangen Kumar. A longitudinal study on ARI among rural under five. Indian journal of comm. Medicine, 2001: vol-xxvi; March: 2001.

10. S. Broor, Panday R.M, Ghosh M. Risk factors for Severe Acute Respiratory Tract Infections in Under-five children, Delhi. Indian journal of pediatrics 2001, Dec.17;1361-7.

11. D Souza RM,. Housing environmental factors and their effects on the health of children in the slums of Karachi, Pakistan. J Biosoc Sci. 1997 Jul; 29(3); 271-81.

12. Shah $\mathrm{N}$ and Ramman $\mathrm{K}$. Risk factors for severe pneumonia in children in Kerala. Journal of tropical pediatrics, 1994: Aug; 4: 201-6.

13. Azizi BH, Zulkifli $\mathrm{HI}$ and Kasim MS. Protective and risk factors for acute respiratory infections in hospitalized urban Malaysian children. Southeast Asian J Trop Med Public Health. 1995 Jun; 26(2): 280-5.

14. Deb SK. ARI survey in Tripura in children under 5 years. Journal of Indian Med Assoc. 1998; April: 96:111-16.

15. Cardosa M R; Cousens SN and Alves FM. Crowding: Risk factor or protective factor for lower respiratory disease in young children in Mexico. BMC Public Health 2004; Jun 3, 4: 19.

16. Barton $T$ and Tumwesigire SG. Environmental risk factors for acute respiratory infections among children of military personnel in Uganda. East Afr Med J. 1995 May; 72(5): 290-4.

17. Smith KR, Sarnet JM, Romieu I, Bruce N. Indoor air pollution in developing countries and acute lower respiratory infection in children. Thorax 2000; 55: 518-32.

18. Mishra V. Indoor air pollution from biomass combustion and acute respiratory illness in preschool age children in Zimbabwe. Int J Epidemiol. 2003 oct; 32(5):847-53. 